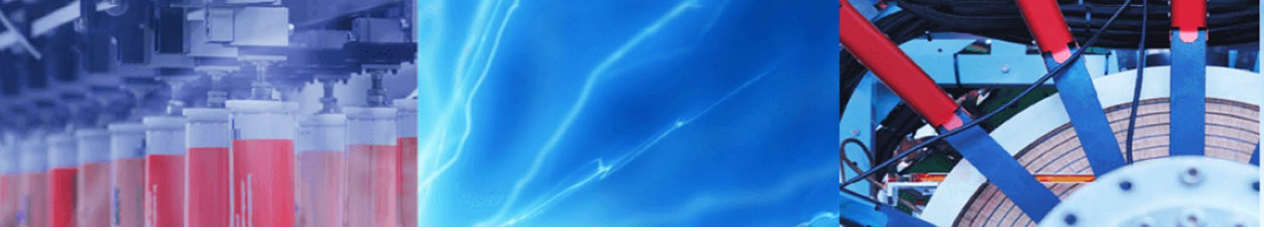

Research Article

\title{
Feasibility of using cigarette butts waste in eco-friendly ceramic roofing tile
}

\author{
L. A. R. Maciel ${ }^{1}$ (I) $\cdot$ R. L. Loiola ${ }^{1}$ J. N. F. Holanda ${ }^{1}$
}

Received: 15 July 2020 / Accepted: 12 October 2020 / Published online: 19 November 2020

(c) Springer Nature Switzerland AG 2020

\begin{abstract}
Cigarette butt is a hazardous solid waste produced in large amounts worldwide, and its improper disposal has been becoming a critical and urgent issue. This work investigates the incorporation of cigarette butt waste as an alternative raw material into an industrial roofing tile body, in replacement to natural roofing tile body by up to $5 \mathrm{wt}$. $\%$. Roofing tile formulations containing cigarette butt waste were pressed and sintered at $1100^{\circ} \mathrm{C}$. The technical properties of the ceramic roofing tile pieces, including linear shrinkage, apparent density, weight loss, water absorption, and flexural strength, were investigated. The microstructural evolution was accompanied by scanning electron microscopy. The test results showed that cigarette butt waste could be used in eco-friendly ceramic roofing tile with good technical properties, in the range up to $5 \mathrm{wt}$ \%, as a partial replacement for traditional roofing tile body, thus giving rise to a new feasible alternative for the sustainable application of cigarette butt waste.
\end{abstract}

Keywords Cigarette butt waste $\cdot$ Roofing tile $\cdot$ Recycling $\cdot$ Technological solution

\section{Introduction}

In the twenty-first century, a significant part of the world population still maintains the habit of smoking tobacco. The world's largest tobacco producers are concentrated in countries of great territorial and population extension, such as China (first), Brazil (second), India (third), and USA (fourth). In 2016, according to the World Health Organization (WHO) [1], the estimated number of tobacco smokers among people aged $\geq 15$ years is about $1.11 \times 10^{9}$. In order to supply this high demand, the tobacco industry produces several trillion cigarettes every year. As a result, people who smoke tobacco in the world generate a significant amount of cigarette butt waste, which is estimated to be around $4.5 \times 10^{12}$ units per year [2]. However, the world population is still growing, so that the levels of cigarette butt waste production are expected to increase in the next years.
The cigarette butt is a solid waste material defined as the cigarette remaining at the conclusion of the smoldering phase following smoking act [3]. It corresponds to about $30 \%$ of the original cigarette length and consists of four major components, such as filter material, unburned tobacco, paper, and ash. This solid waste is considered a hazardous and highly polluting due to the significant amount of toxic chemical compounds that are present in each component of this one [3-7]. In addition, the filter material is mainly produced from cellulose acetate that is slow to biodegrade and can remain in the environment for several years [8]. In view of this, the cigarette butt waste, when disposed of directly into the environment without any treatment, can cause negative impacts on terrestrial and aquatic ecosystems, landscapes, and public health. The landfilling and incineration methods have been tested for the disposal of cigarette butt waste generated in large urban centers and cities [9]. However, these methods

L. A. R. Maciel, luismaciel@globo.com | ${ }^{1}$ Laboratory of Advanced Materials, Group of Ceramic Materials, Northern Fluminense State University, Campos dos Goytacazes, RJ 28013-602, Brazil. 
are not considered feasible in terms of environmental and economic sustainability. Although enormous effort has been doing in the last years, a sustainable approach for the disposal of cigarette butt waste has not yet been established.

In recent years, several alternative uses for cigarette butt waste have been tested. For example, it has been tested as corrosion inhibitor [10], biofilm carrier [11], activated carbon [12, 13], preparation of cellulose pulp [14], bituminous mixture [15], concrete [16], and as carbon source for supercapacitors and adsorbents [17]. Besides that, the use of cigarette butt waste in fired clay bricks is receiving increasing attention worldwide [2, 5, 9, 18-22]. However, the use of cigarette butt waste to produce ceramic roofing tiles has not yet been investigated. The ceramic roofing tiles are components intended for the assembly of a watertight cover, of discontinuous application [23]. When compared to the fired clay brick, the ceramic roofing tile has a higher added value, lower water absorption (open porosity), and higher density, and is waterproof. Some favorable reasons for using cigarette butt waste on ecofriendly ceramic roofing tile include the following: (1) The roofing tile bodies are primarily composed of mixture of clays, which allows a wide variation of their chemical and mineral composition; (2) the high temperature employed in the sintering step allows the destruction and volatilization of dangerous components present in the cigarette butt waste; (3) heavy metals and toxic compounds can be inertized through fixation in the sintered ceramic matrix; and (4) the industrial route for the manufacture of ceramic roofing tiles is little modified.

Therefore, considering the growing concerns related to the disposal of cigarette butt waste, the present study focuses on the feasibility of introducing cigarette butt waste into an industrial roofing tile body as a replacement for traditional non-renewable raw materials.

\section{Materials and methods}

In this work, industrial roofing tile body and cigarette butt waste were selected as starting raw materials. The cigarette butt waste was collected from a company located in southeastern Brazil (São João da Barra-RJ), which provides an area for smokers with a metal receptacle. The chemical analysis of the industrial roofing tile body used in this work (Table 1 ) was determined by using $X$-ray fluorescence spectrometer (PW 2400 model; Philips). The mineralogical analysis was performed by $\mathrm{X}$-ray diffraction in a conventional diffractometer (XRD 7000 model, Shimadzu) using $\mathrm{Cu}-\mathrm{Ka}$ radiation at a scanning speed of $\left.1.5^{\circ}(2 \theta) / \mathrm{min}\right)$. In mineral terms, it is mainly composed of kaolinite, and in
Table 1 Chemical analysis of the industrial roofing tile body (wt.\%)

\begin{tabular}{lr}
\hline $\mathrm{SiO}_{2}$ & 49.80 \\
$\mathrm{Al}_{2} \mathrm{O}_{3}$ & 26.56 \\
$\mathrm{Fe}_{2} \mathrm{O}_{3}$ & 7.63 \\
$\mathrm{~K}_{2} \mathrm{O}$ & 1.44 \\
$\mathrm{Na}_{2} \mathrm{O}$ & 0.49 \\
$\mathrm{CaO}$ & 0.46 \\
$\mathrm{MgO}$ & 0.77 \\
$\mathrm{TiO}_{2}$ & 1.11 \\
$\mathrm{MnO}$ & 0.05 \\
$\mathrm{P}_{2} \mathrm{O}_{5}$ & 0.14 \\
$\mathrm{Lol}$ at $1000{ }^{\circ} \mathrm{C}$ & 11.57 \\
\hline
\end{tabular}

Table 2 Compositions of the roofing tile formulations (wt.\%)

\begin{tabular}{lcl}
\hline Formulation & Clayey body & $\begin{array}{l}\text { Cigarette } \\
\text { butt waste }\end{array}$ \\
\hline MLA1 & 100,00 & 0,00 \\
MLA2 & 98,75 & 1,25 \\
MLA3 & 97,50 & 2,50 \\
MLA4 & 96,25 & 3,75 \\
MLA5 & 95,00 & 5,00 \\
\hline
\end{tabular}

minor amounts, there are quartz, gibbsite, goethite, and illite [24].

Selected roofing tile bodies containing $0,1.25,2.5,3.75$, and 5 wt. \% cigarette butt waste were prepared (Table 2). In this study, the industrial roofing tile body was replaced with increasing amounts of cigarette butt waste. The raw materials were dry-ground and then sieved until the fraction passing in a 42-mesh (355 $\mu \mathrm{m}$ ASTM) screen. Particularly, the cigarette butt waste was ground through the knife mill. The compositions of the proposed formulations (Table 2) were mixed and homogenized by using a cylindrical mixer for $20 \mathrm{~min}$. The moisture content (moisture mass/dry mass) was adjusted to $7 \%$.

The loss on ignition (Lol) of the cigarette butt waste sample was determined by $\mathrm{Lol}=(\mathrm{Md}-\mathrm{Mc}) / \mathrm{Md} \times 100$, in which Md is the weight of the dry sample at $110^{\circ} \mathrm{C}$ and $\mathrm{Mc}$ is the weight of the calcined sample at $1100^{\circ} \mathrm{C}$ during $2 \mathrm{~h}$. The qualitative elementary chemical analysis was performed using the energy-dispersive $\mathrm{X}$-ray spectrometer (EDX 700; Shimadzu). The morphological aspects of the cigarette butt waste particles were examined by scanning electron microscopy (SEM SSX-550, Shimadzu). The particle-size analysis of the roofing tile bodies was performed by a combination of sieving and sedimentation procedures, according to NBR 7181 [25]. Plasticity tests according to the Atterberg method were also carried out.

Rectangular roofing tile pieces (size, $11.5 \mathrm{~cm} \times 2.54 \mathrm{~cm} \times 1.0 \mathrm{~cm}$ ) were prepared by uniaxial 
pressing at $24 \mathrm{MPa}$ and then dried in an oven $\left(110^{\circ} \mathrm{C}\right.$ for $24 \mathrm{~h}$ ). The green roofing tile pieces produced were sintered at $1100^{\circ} \mathrm{C}$ for $2 \mathrm{~h}$ in a laboratory muffle kiln. In this study, a slow-firing cycle ( $24 \mathrm{~h}$ cold to cold) was considered to simulate an actual sintering process used in the manufacture of industrial roofing tile.

Linear shrinkage values were determined by measuring variation in the length of rectangular piece upon drying and firing according to ASTM C326-09 [26]. The values of water absorption were determined according to NBR 15,310 [23]. The apparent density and apparent porosity were determined by the Archimedes method [27]. The flexural strength (FS) was determined by a three-point bending test (Model 5588, Instron) at a loading rate of $0.5 \mathrm{~mm} / \mathrm{min}$ according to $\mathrm{FS}=3 \mathrm{PL} / 2 \mathrm{bd}^{2}$, where $\mathrm{P}$ is the load at rupture, $L$ is the distance between supports, $b$ is the specimen width, and d is its thickness. Scanning electron microscopy operating at $15 \mathrm{kV}$ was used to evaluate gold-coated fracture surfaces of the sintered specimens by secondary electron imaging (SEI).

\section{Results and discussion}

The loss-on-ignition (Lol) behavior of cigarette butt waste found was very high weight loss of about $89.47 \%$. This finding is mainly attributed to the organic nature of the cigarette butt waste, which tends to be destroyed when exposed to high temperature. In fact, cigarette butt waste is mainly composed of cellulose acetate, which is an organic ester derived of cellulose. The thermal decomposition of cellulose acetate is mainly related to dehydration and acetic acid removal with a final weight loss of about $88 \%$ [28], which is in accordance with the Lol value obtained in this study. This result is very important because the cigarette butt waste facilitates the development of porosity in the sintered structure; consequently, it can influence the densification and technical properties of the roofing tile body. It was also found about $10.53 \mathrm{wt} . \%$ of a residual white product (ash) generated during the thermal decomposition of the cigarette butt waste. Such an ash will be incorporated into sintered roofing tile piece.

The elements present in the cigarette butt waste used in this study were only detected qualitatively by EDX analysis. The elements found in the cigarette butt waste were $\mathrm{Ca}, \mathrm{K}$, $\mathrm{Ti}, \mathrm{Cl}, \mathrm{Fe}, \mathrm{Si}, \mathrm{V}, \mathrm{S}, \mathrm{Mn}, \mathrm{Zr}$, and $\mathrm{Sr}$. This result is in accordance with the literature $[3,5,29]$, where the elements detected in cigarette butt waste are well documented.

Morphological aspects of the starting raw materials are presented in Fig. 1a, b. It can be observed that the cigarette butt waste is mainly composed of elongated slat-like plates of cellulose acetate in a completely random way, as shown in the SEM image of Fig. 1a. In addition, the plates have a smooth and non-porous texture. The industrial roofing tile body used in this work is mainly composed of lamellar plate-shaped particles highly agglomerated that are coming from the kaolinite, as shown in Fig. 1b.

The particle size data of the prepared roofing tile bodies are shown in Table 3. It was found that the roofing tile bodies have a very similar granulometric behavior. All of them had a high amount of clay fraction $(<2 \mu \mathrm{m})$ with about $52-56 \%$, which is mainly related to the presence of kaolinite. Thus, the cigarette butt waste added in a small amount (up to 5 wt.\%) had little influence on the granulometric behavior of the industrial roofing tile body used in this work.

Table 4 gives the plasticity of the roofing tile bodies. It was evaluated by the Atterberg plastic index (PI) given by $\mathrm{PI}=\mathrm{UPL}-\mathrm{LPL}$, where UPL is the upper plastic limit and LPL is the lower plastic limit. The results revealed that the ceramic bodies had high plasticity $(\mathrm{PI}=29.7-30.5 \%)$, which is adequate for the industrial roofing tiles production. In terms of soil mechanics, the roofing tile bodies containing cigarette butt waste could be classified as high-plasticity inorganic clays [30]. This is in accordance with the granulometric behavior in which the roofing tile bodies are rich in clay fraction $(<2 \mu \mathrm{m})$. All roofing tile bodies prepared in this study had plasticity adequate for industrial roofing tile production [31]. Also, this analysis revealed that the incorporation of the cigarette butt waste had little influence on the plasticity behavior of the roofing tile bodies, according to the granulometric data in Table 3.

Table 5 gives the technological properties of the roofing tile pieces after drying at $110^{\circ} \mathrm{C}$. The results indicated that there are no significant differences on the drying shrinkage of the green roofing tile pieces, independently of the amount of incorporated cigarette butt waste. The green roofing tile pieces had low drying shrinkage values ( $L S=0.15-0.17 \%)$, indicating suitability for industrial production. The drying density of the roofing tile pieces was within the range between 1.68 and $1.73 \mathrm{~g} / \mathrm{cm}^{3}$. However, the drying density was observed to decrease, as the cigarette butt waste amount increased up to $5 \mathrm{wt} . \%$. This finding can be attributed to the lower density $\left(1.32 \mathrm{~g} / \mathrm{cm}^{3}\right)$ of cellulose acetate [32], which is the main component of the cigarette butt waste. The drying flexural strength values obtained (FS $=1.10-2.15 \mathrm{MPa}$ ) are suitable for manufacturing ceramic roofing tile. It was observed that the cigarette butt waste improved the dry mechanical strength of the roofing tile pieces. This effect is related to a better compacting response in dry state of the roofing tile pieces containing cigarette butt waste.

Figure 2 shows the fracture surface of MLA1, MLA3, and MLA5 formulations sintered at $1100^{\circ} \mathrm{C}$. SEM micrographs illustrate the evolution of the sintered microstructure of roofing tile pieces as the amount of cigarette butt waste 
Fig. 1 Morphology of the starting raw materials particles: a cigarette butt waste; and $\mathbf{b}$ roofing tile body
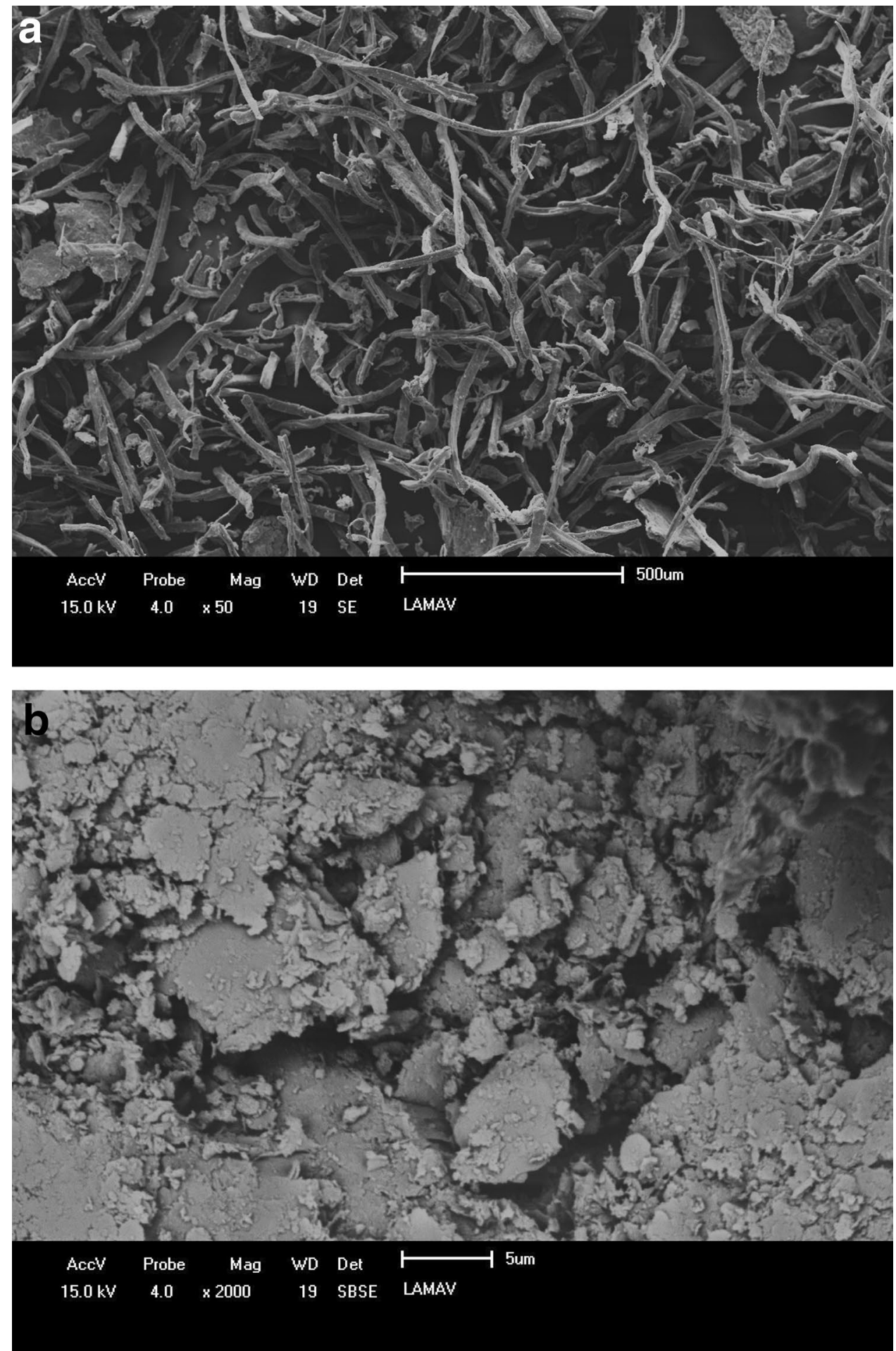

increases. It can be observed in Fig. 2b, c that the MLA3 and MLA5 formulations had a sintered microstructure slightly more porous than the waste-free pieces (Fig. 2a). This means that the control of the amount of cigarette butt waste (up to $5 \mathrm{wt} . \%$ ) into roofing tile body tends to cause only small changes on the microstructure. All sintered pieces presented an advanced sintering stage. The development of the microstructure with signs of vitrification in the sintered aluminosilicate matrix can be observed. In fact, at $1100^{\circ} \mathrm{C}$ a glassy phase starts to emerge and reduces the porosity of the ceramic ware. Such a glassy phase formed is also highly beneficial because it improves the chemical resistance against leaching of toxic metals present in the cigarette butt waste. 
Table 3 Particle size distribution of the roofing tile bodies (\% in mass)

\begin{tabular}{llll}
\hline Formulation & Clay $(<2 \mu \mathrm{m})$ & Silt $(2 \leq \mathrm{x}<60 \mu \mathrm{m})$ & $\begin{array}{l}\text { Sand } \\
(>60 \mu \mathrm{m})\end{array}$ \\
\hline MLA1 & 56 & 35 & 9 \\
MLA3 & 55 & 33 & 12 \\
MLA5 & 52 & 35 & 13 \\
\hline
\end{tabular}

Table 4 Atterberg limits for the roofing tile bodies (\%)

\begin{tabular}{llll}
\hline Formulation & UPL & PI & LPL \\
\hline MLA1 & 64.0 & 33.5 & 30.5 \\
MLA3 & 64.9 & 35.2 & 29.7 \\
MLA5 & 64.5 & 34.8 & 29.7 \\
\hline
\end{tabular}

Table 5 Technological properties of the roofing tile pieces after drying at $110^{\circ} \mathrm{C}$

\begin{tabular}{llll}
\hline Formulation & $\mathrm{LS}(\%)$ & $\mathrm{BD}\left(\mathrm{g} / \mathrm{cm}^{3}\right)$ & $\mathrm{FS}(\mathrm{MPa})$ \\
\hline MLA1 & $0.15 \pm 0.02$ & $1.73 \pm 0.01$ & $1.10 \pm 0.10$ \\
MLA2 & $0.16 \pm 0.02$ & $1.72 \pm 0.01$ & $1.58 \pm 0.44$ \\
MLA3 & $0.15 \pm 0.02$ & $1.70 \pm 0.03$ & $2.15 \pm 0.09$ \\
MLA4 & $0.16 \pm 0.03$ & $1.70 \pm 0.01$ & $1.99 \pm 0.16$ \\
MLA5 & $0.17 \pm 0.02$ & $1.68 \pm 0.01$ & $2.00 \pm 0.32$ \\
\hline
\end{tabular}

LS-linear shrinkage; BD—bulk density; FS-flexural strength

The quality of the ceramic roofing tile pieces after sintering at $1100^{\circ} \mathrm{C}$ was evaluated on the basis of their technical properties: linear shrinkage, apparent density, weight loss, water absorption, and flexural strength. The sintered pieces with 0 wt.\% cigarette butt waste (MLA1 formulation, $100 \%$ industrial roofing tile body) were used as reference. The incorporation of cigarette butt waste had little influence on the color of the ceramic roofing tile pieces sintered at $1100^{\circ} \mathrm{C}$ (Fig. 3), presenting reddish-yellow color because of the presence of iron oxide $\left(\mathrm{Fe}_{2} \mathrm{O}_{3}\right)$, as shown in Table 1. Such a sintering color obtained is suitable for industrial ceramic roofing tile production. In addition, no roofing tile piece has shown any indication of surface stains and defects due to the incorporation of cigarette butt waste.

The linear shrinkage values for the roofing tile pieces are shown in Fig. 4. The roofing tile pieces presented linear shrinkage values within the $6.97-8.42 \%$ range. The results indicated that the effect of the incorporation of the cigarette butt waste caused only small variations within the dispersion limits. In view of this, a good dimensional control of the roofing tile pieces containing up to $5 \mathrm{wt} . \%$ of cigarette waste can be obtained. The values of linear shrinkage also revealed that the roofing tile pieces were sintered prevalently through the viscous flow mechanism, indicating the progress of vitrification (formation of glassy phase) [33].

The apparent density of the roofing tile pieces sintered at $1100{ }^{\circ} \mathrm{C}$ is shown in Fig. 5. The apparent density of the sintered pieces was in the range of $1.91-2.04 \mathrm{~g} / \mathrm{cm}^{3}$, which is typical of ceramic roofing tile materials. However, the apparent density had a tendency to decrease when the cigarette butt waste amount was increased. The densification behavior of the roofing tile pieces containing cigarette butt waste is quite complex and is associated with several simultaneous opposing factors influencing the densification, namely: (1) The decomposition of the cigarette butt waste during the sintering step tends to increase weight loss (Fig. 6); (2) sintering by viscous flux mechanism tends to reduce the pore volume in the material structure; (3) the heat produced by the combustion of the cigarette butt waste tends to aid the sintering of the roofing tile body; and (4) the ash generated during combustion of the cigarette butt waste also helps in the densification of the roofing tile pieces.

Figure 7 shows the water absorption values of the sintered roofing tile pieces. This physical property is directly related to the open pores available, which strongly impacts the microstructure, impermeability, mechanical strength, and durability of ceramic roofing tile materials. The roofing tile pieces produced in this work reached the values of water absorption between 11.83 and $15.29 \%$. It was also observed that the water absorption tends to increase with addition of cigarette butt waste. This result is in good agreement with the apparent density (Fig. 5) and apparent porosity (Fig. 8). Conversely, the values of water absorption found are in line with the dense microstructure of the sintered pieces (Fig. 2). Fundamentally, the formation of glassy phase during sintering contributed to eliminating a substantial amount of open pores. The water absorption (WA) is used to evaluate the technical quality of ceramic roofing tile materials (WA $\leq 20 \%$ ) [23]. As can be seen in Fig. 7, all roofing tile pieces achieved the water absorption specification in terms of Brazilian standardization, regardless of the added cigarette butt waste amount.

Flexural strength of the sintered roofing tile pieces is shown in Fig. 9. The flexural strength is also a key factor in terms of technical quality of ceramic roofing tile materials. The results of flexural strength found are quite correlated with the other physical properties and sintered microstructure. The flexural strength values of the roofing tile pieces, considering the dispersion limits, reached only small variations with cigarette butt waste addition (8.24-12.36 MPa). In short, all sintered pieces at $1100^{\circ} \mathrm{C}$ met flexural strength recommended for industrial roofing tile production ( $>6.5 \mathrm{MPa}$ ) [34]. This is an important technical issue, because the physical and mechanical properties 
Fig. 2 SEM micrographs of the fracture surfaces of the ceramic roofing tile pieces: a MLA1; $\mathbf{b}$ MLA3; and c MLA5
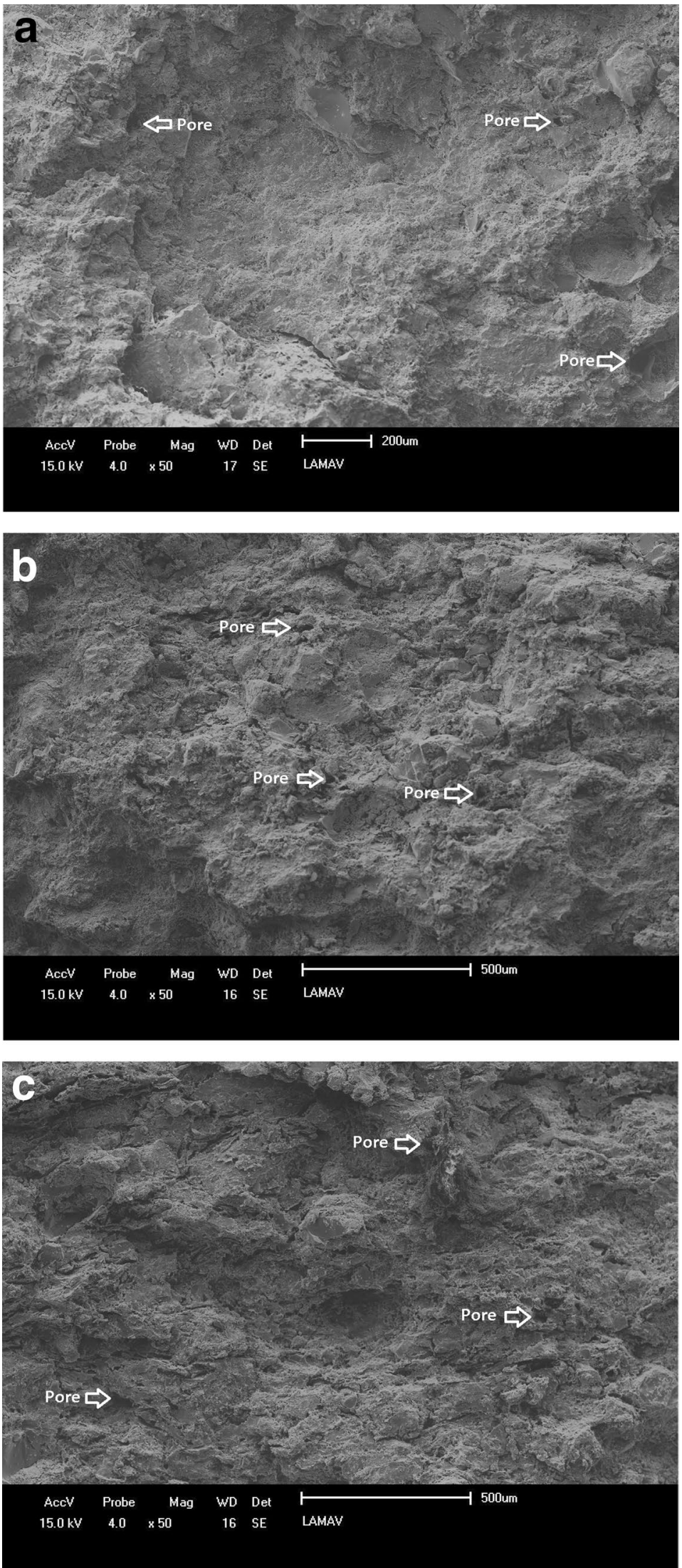


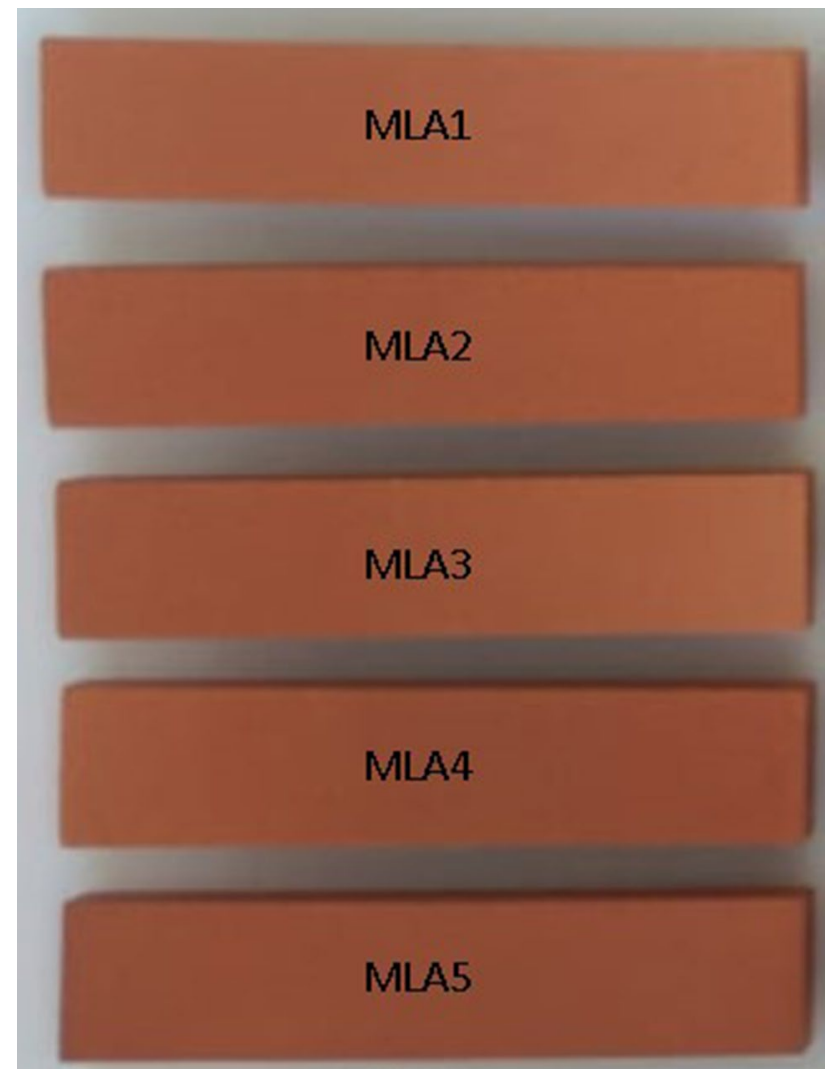

Fig. 3 Roofing tile pieces sintered at $1100^{\circ} \mathrm{C}$ of technological interest of the ceramic roofing tile pieces produced had little changes due to addition of cigarette butt waste (up to $5 \mathrm{wt} . \%$ ). In connection with this, the feasibility of cigarette butt waste to produce ceramic roofing tiles and prevent high environmental impacts must also be highlighted.

\section{Conclusions}

The results of this study suggest a feasible method of managing the recycling of cigarette butt waste in a sustainable way to produce eco-friendly ceramic roofing tiles. The cigarette butt waste used in this study is essentially an organic material that decomposes during the sintering process. As such, it acts as a pore-forming agent. It was found that the cigarette butt waste incorporated into industrial roofing tile body caused only small changes on the technical properties and sintered microstructure. The incorporation of cigarette butt waste, in the range up to 5 wt.\%, allows the production of eco-friendly ceramic roofing tile with good technological properties. This result is of high practical, economic, and environmental interest due to the possibility of valorization of a solid waste with a high potential for environmental pollution that is present in huge amounts in the environment through inadequate disposal.

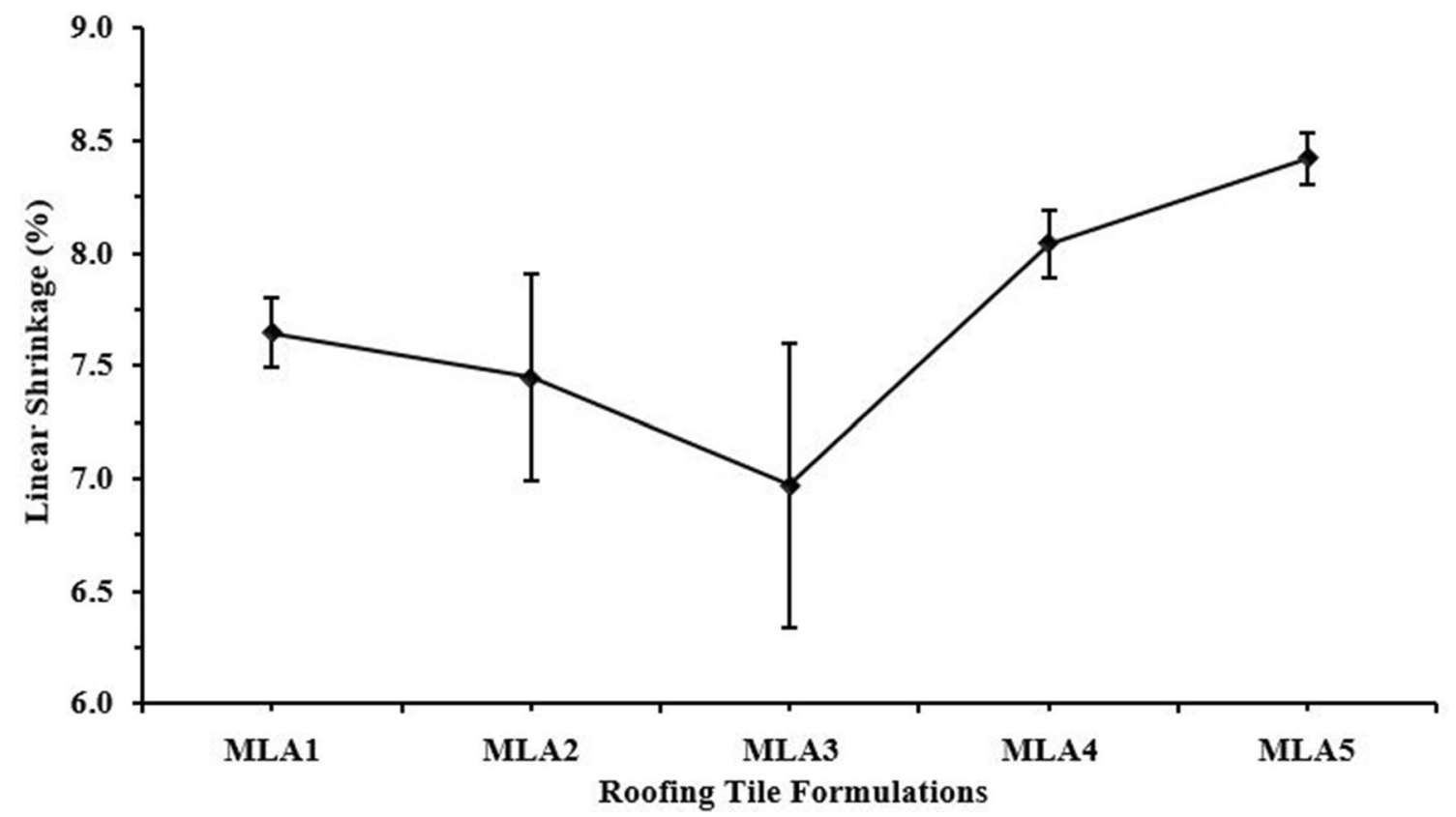

Fig. 4 Linear shrinkage of the roofing tile pieces versus waste amount 


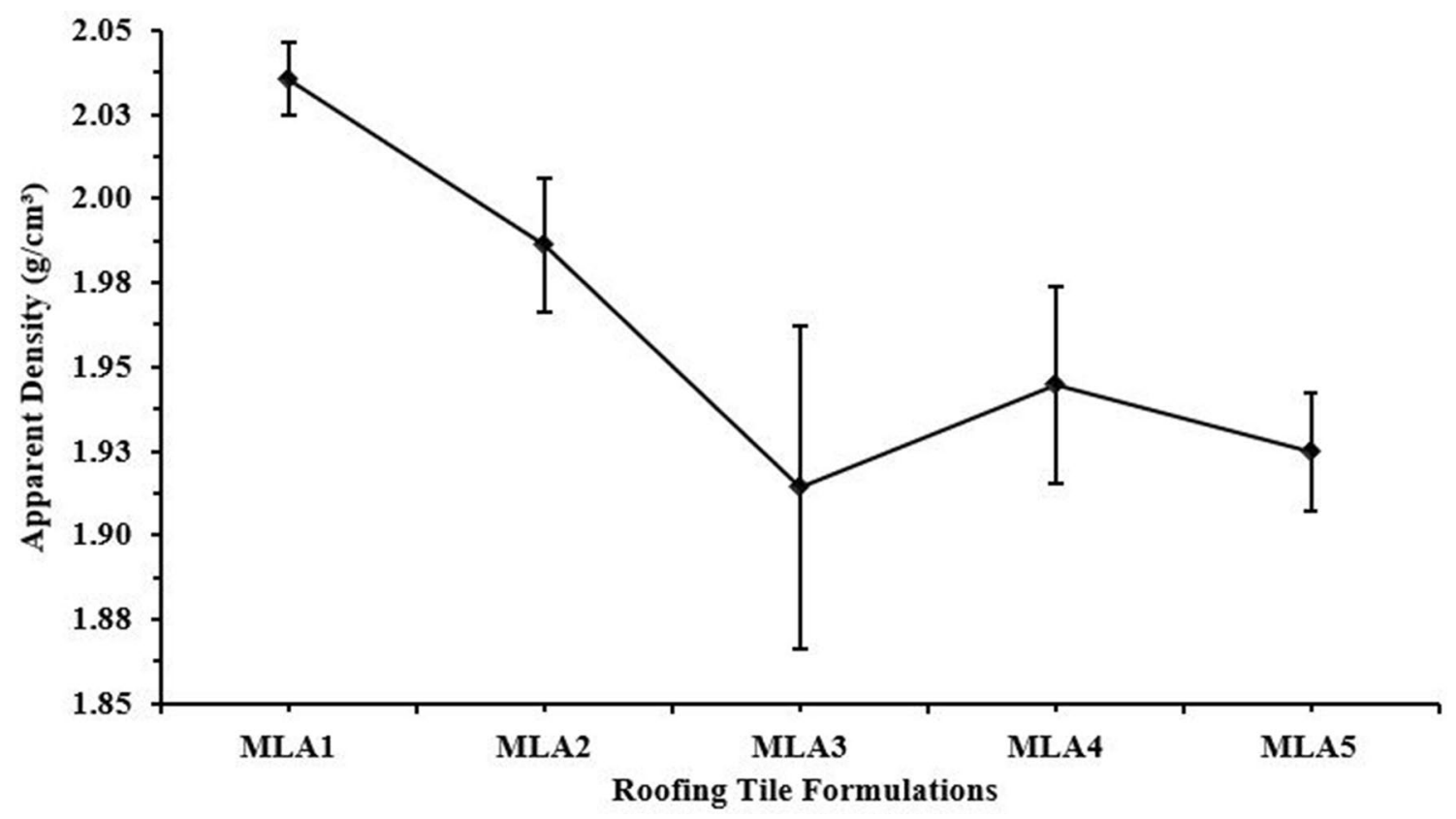

Fig. 5 Apparent density of the roofing tile pieces versus waste amount

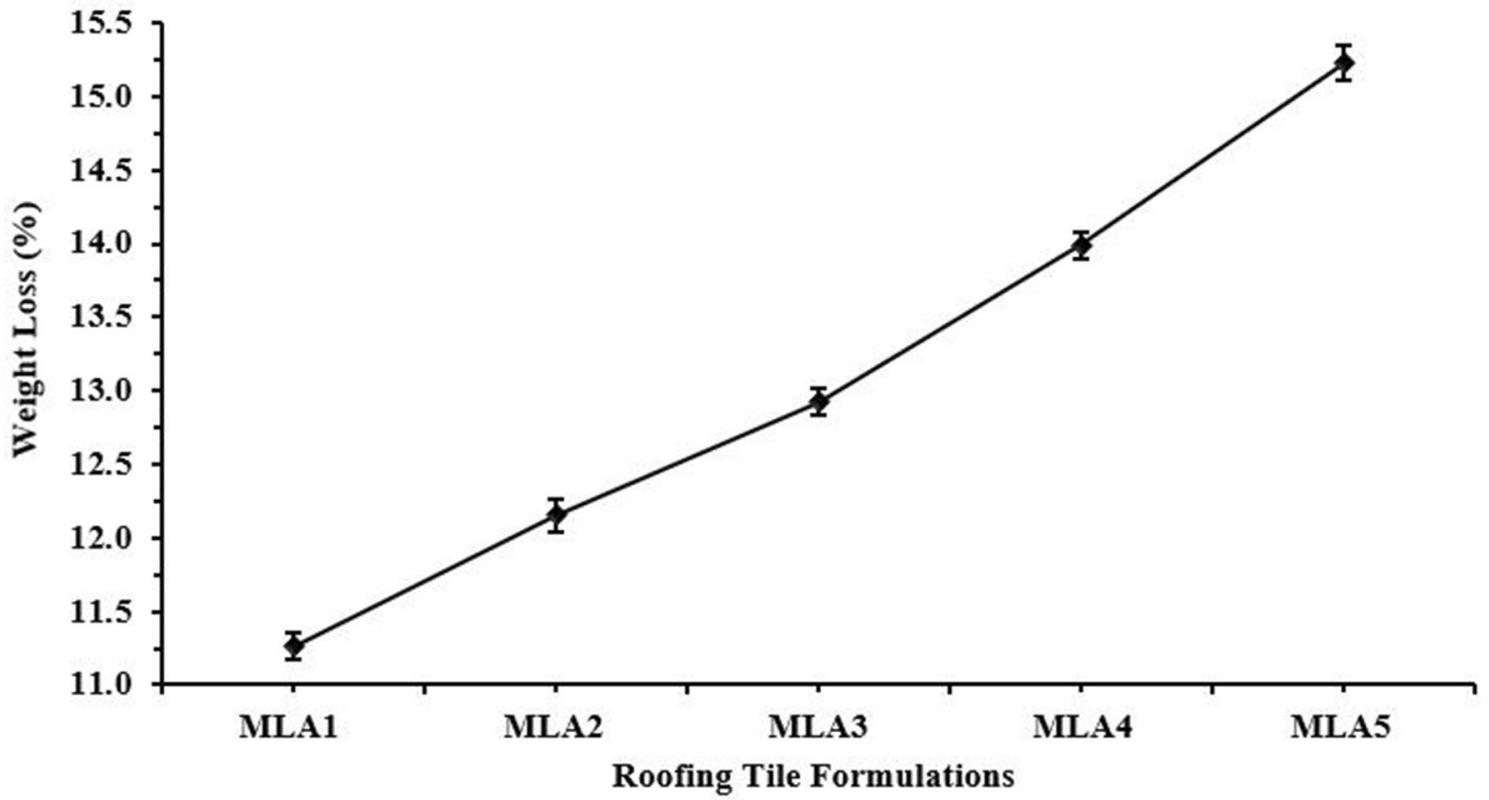

Fig. 6 Weight loss of the roofing tile pieces versus waste amount 


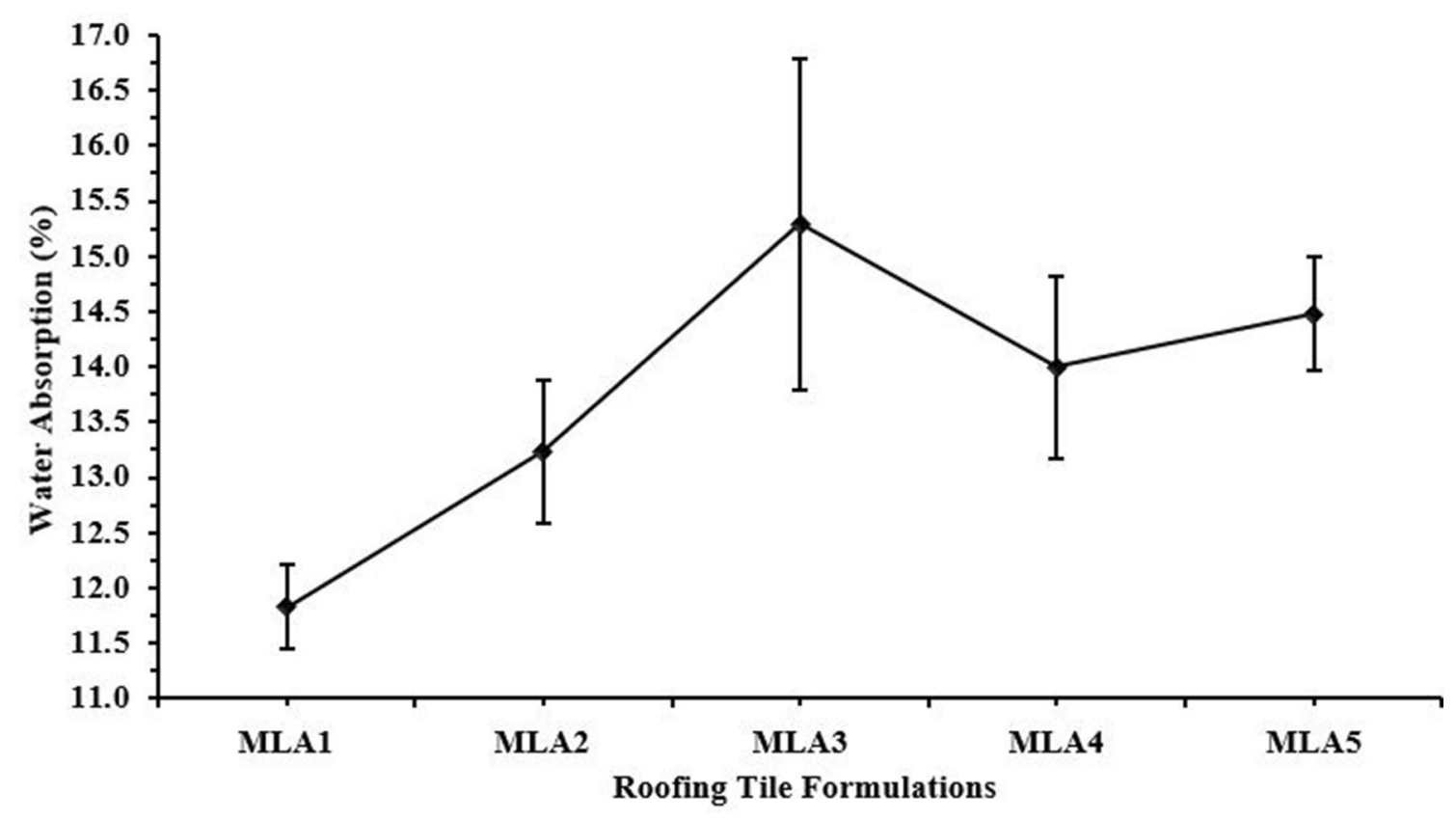

Fig. 7 Water absorption of the roofing tile pieces versus waste amount

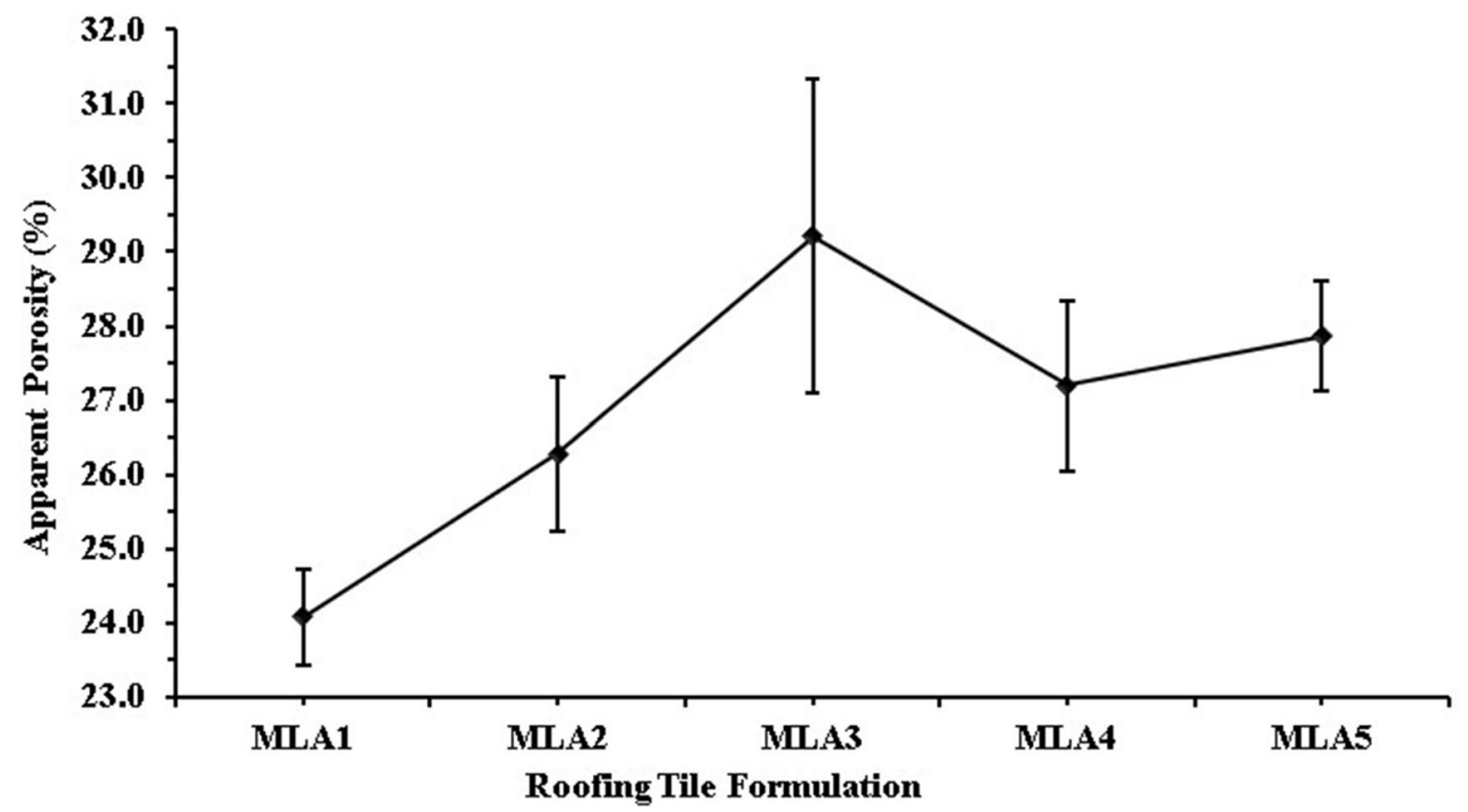

Fig. 8 Apparent porosity of the roofing tile pieces versus waste amount 


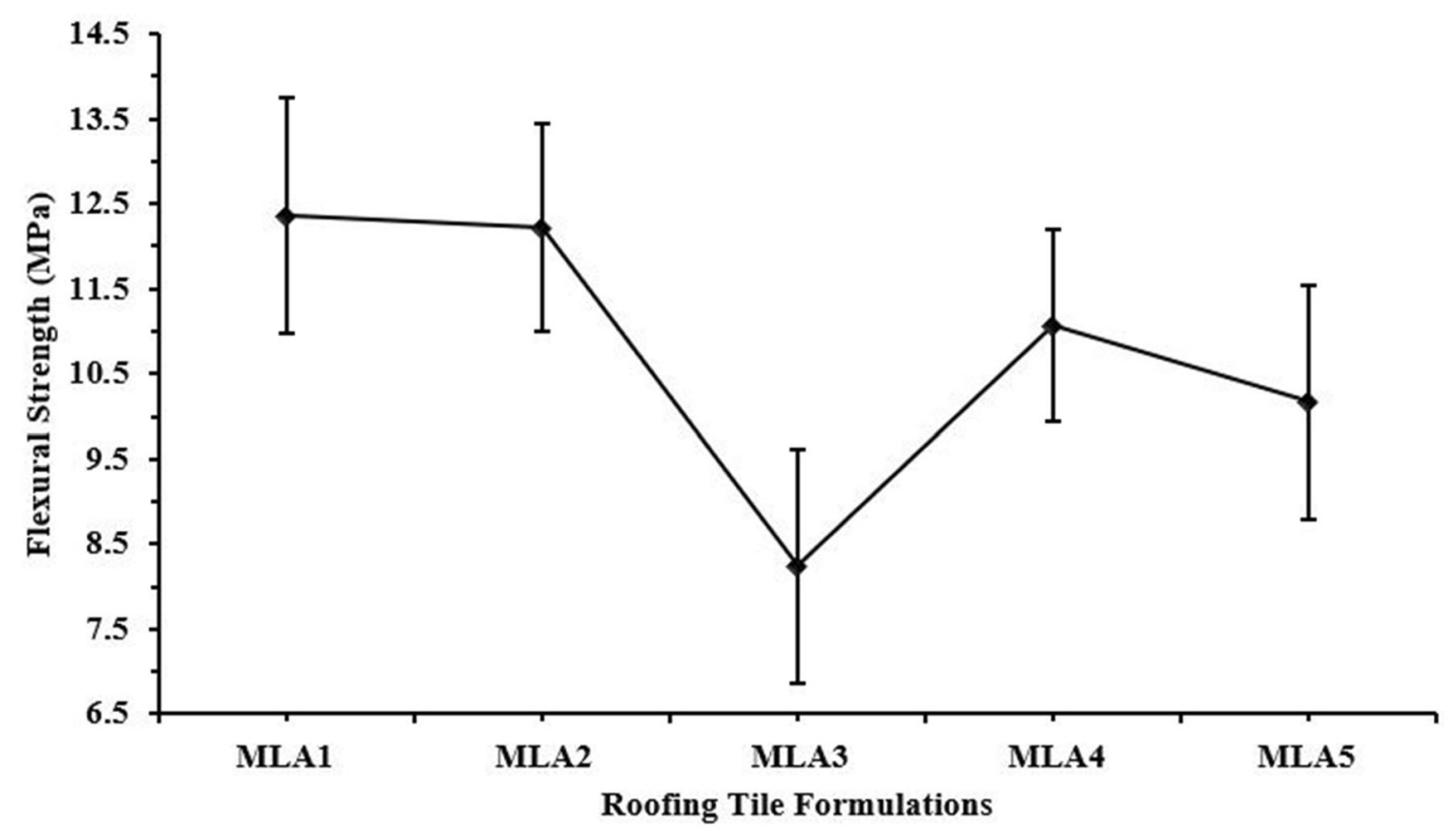

Fig. 9 Flexural strength of the roofing tile pieces versus waste amount

Acknowledgements The authors thank the National Council for Scientific and Technological Development-CNPq (Grant No. 307507/2019-0) and Foundation for Research Support of the State of Rio de Janeiro-FAPERJ (Grant No. E-26/203.013/2016) for supporting this work.

\section{Compliance with ethical standards}

Conflict of interest The authors declare that they have no conflict of interest.

\section{References}

1. World Health Organization (WHO) (2018) WHO global report on trends in prevalence of tobacco smoking 2000-2025. Second Edition, Geneva

2. Jovanović M, Mujkanović A, Tutić E (2020) Cigarette butts and waste coffee grounds as additives to brick clay. Holistic Approach Environ. 101 1-9. https://doi.org/https://doi. org/10.33765/thate.10.1.1

3. Poppendieck D, Khurshid S, Emmerich S (2016) Measuring airborne emissions from cigarette butts: literature review and experimental plan, NISTIR 8147 Report. Natl Inst Stand Technol . https://doi.org/10.6028/NIST.IR.8147

4. Slaughter E, Gersberg RM, Watanabe K, Rudolph J, Stransky C, Novotny TE (2011) Toxicity of cigarette butts, and their chemical components, to marine and freshwater fish. Tob Control 20:i25i29. https://doi.org/10.1136/tc.2010.040170

5. Kadir AA, Sarani NA (2015) Cigarette butts pollution and environmental impact-a review. Appl Mech Mater 773774:1106-1110. https://doi.org/10.4028/www.scientific.net/ AMM.773-774.1106

6. Rebischung F, Chabot L, Biaudet H, Pandard P (2018) Cigarette butts: a small but hazardous waste, according to European regulation. Waste Manag 82:9-14. https://doi.org/10.1016/j. wasman.2018.09.038

7. Torkashvand J, Farzadkia M, Sobhi HR, Esrafili A (2020) Littered cigarette butt as a well-known hazardous waste: a comprehensive systematic review. J Hazard Mater 383:e121242. https://doi. org/10.1016/j.jhazmat.2019.121242

8. Puls J, Wilson SA, Holter D (2011) Degradation of cellulose acetate-based materials: a review. J Polym Environ 19(1):152-165. https://doi.org/10.1007/s10924-010-0258-0

9. Mohajerani A, Kadir AA, Larobina L (2016) A practical proposal for solving the world's cigarette butt problem: recycling in fired clay bricks. Waste Manag 52:228-244. https://doi.org/10.1016/j. wasman.2016.03.012

10. Zhao J, Zhang N, Qu C, Wu X, Zhang J, Zhang X (2010) Cigarette butts and their application in corrosion inhibition for N80 steel at $90^{\circ} \mathrm{C}$ in hydrochloric acid solution. Ind Eng Chem Res 49(8):3986-3991. https://doi.org/10.1021/ie100168s

11. Sabzali A, Nikaeen M, Bina B (2012) Performance evaluation of cigarette filter rods as a biofilm carrier in an anaerobic moving bed biofilm reactor. Environ Technol 33(15):1803-1810. https:// doi.org/10.1080/09593330.2011.646317

12. Salman MS, Yazdi SK, Hosseini S, Gargari MK (2014) Effect of nitric acid modification on porous characteristics of mesoporous char synthesized from the pyrolysis of used cigarette filters. J Environ Chem Eng 2(3):1301-1308. https://doi.org/10.1016/j. jece.2014.04.005

13. Soltani SM, Yazdi SK, Hosseini S, Bayestie I (2015) Lead removal from aqueous solution using non-modified and nitric acidmodified charred carbon from the pyrolysis of used cigarette filters. Desalin Water Treat 53(1):126-138. https://doi. org/10.1080/19443994.2013.835751

14. Teixeira MBH, Duarte MAB, Garcez LR, Rubim JC, Gatti TH, Suarez PAZ (2017) Process development for cigarette butts recycling into cellulose pulp. Waste Manag 60:140-150. https://doi. org/10.1016/j.wasman.2016.10.013

15. Cui Y, Wu Z, Li Y, Yang H (2018) Experimental study on determining the optimum cigarette butt content of modified bituminous 
mixture of cigarette butts. J Civ Eng Archit 12:447-453. https:// doi.org/10.17265/1934-7359/2018.06.005

16. Tao L, Zhaojing Z, Jinliang Z, Chaowei S, Yanjun J (2019) Experimental study on uniaxial compressive strength of concrete incorporated with cigarette butts. . IOP Conf Ser Earth Environ Sci 233:1-6. https://doi.org/10.1088/1755-1315/233/5/052030

17. Li L, Jia C, Zhu X, Zhang S (2020) Utilization of cigarette butt waste as functional carbon precursor for supercapacitors and adsorbents. J Clean Prod 256:e120326. https://doi.org/10.1016/j. jclepro.2020.120326

18. Kadir AA, Mohajerami A (2015) Effect of heating rate on gas emissions and properties of fired clay bricks and fired clay bricks incorporated with cigarette butts. Appl Clay Sci 104:269-276. https://doi.org/10.1016/j.clay.2014.12.005

19. Sujay SM, Tejashri AK, Pooja GB (2017) Reuse of cigarette butt for manufacturing bricks. Int J Adv Res Sci Eng 6(3):464-470

20. Jain J, Dubey M (2018) Experimental study of bricks prepared by blending clay with cigarette butts. Int J Sci Res Develop 6(4):1423-1426

21. Gokulnath M, Krishnan PH, Jayashree S, Caroline JJ, Prakash NA (2019) Utilisation of cigarette butts in clay bricks. Int Res J Eng Technol 6(3):3240-3242

22. Kurmus $H$, Mohajerani $A$ (2020) The toxicity and valorization options of cigarette butts. Waste Manag 104:104-118. https:// doi.org/10.1016/j.wasman.2020.01.011

23. ABNT (2005) NBR 15310, Ceramic Components - Ceramic Roof Tiles: Terminology, Requirements and Testing Methods. Brazilian Association of Technical Standards

24. Souza GP, Sousa SJG, Terrones LAH, Holanda JNF (2005) Mineralogical analysis of Brazilian ceramic sedimentary clays used in red ceramic. Cerâmica 51(320):381-386. https://doi.org/10.1590/ S0366-69132005000400012

25. ABNT (1984) NBR 7181, Soil: Granulometric Analysis. Brazilian Association of Technical Standards

26. ASTM (2018) ASTM C326-09, Standard Test Method for Drying and Firing Shrinkages of Ceramic Whiteware Clays. ASTM International, West Conshohocken, PA
27. Santos PS (1989) Clay science and technology. Edgard Blücher, São Paulo, pp 196-200

28. Soltani SM, Yazdi SK (2012) The effect of pyrolysis time and heating rate on the surface area and pore size properties of porous carbon obtained from the pyrolysis of a cellulosic waste. In Proceedings of 2 nd International Conference on Environment and Industrial Innovation, Singapore. 11-14

29. Benavente MJ, Caballero MJA, Silvero G, López-Coca I, Escobar VG (2018) Cellulose acetate recovery from cigarette butts. Proceedings 2(20):1447. https://doi.org/10.3390/proceedings2201 447

30. Campos LFA, Macedo RS, Kiylhana PK, Ferreira HC (1999) Plasticity characteristics of clays for use in structural clay products. Cerâmica 45(295):140-145. https://doi.org/10.1590/S0366 $-69131999000500006$

31. Dondi M (2003) Technological characterization of clay materials: experimental methods and data interpretation. Int Ceram J 55-59.

32. Chen J (2014) Synthetic textile fibers: regenerated cellulose fibers. In: Sinclair R (ed) Textiles and fashion: materials design and technology. Woodhead Publishing, Cambridge, pp 79-95

33. Milheiro FAC, Freire MN, Silva AGP, Holanda JNF (2005) Densification behaviour of a red firing Brazilian kaolinitic clay. Ceram Int 31(5):757-763. https://doi.org/10.1016/j.ceramint.2004.08.010

34. Godinho KO, Holanda JNF, Silva AGP (2005) Production and evaluation of technological properties of ceramic specimens based on the mix clay-recycled glass. Cerâmica 51(320):419-427. https ://doi.org/10.1590/S0366-69132005000400018

Publisher's Note Springer Nature remains neutral with regard to jurisdictional claims in published maps and institutional affiliations. 